\title{
Pengaruh pembebanan terhadap kecepatan kerja roll conveyor
}

\author{
Syafrizal ${ }^{1 *}$, Adolf Asih Supriyanto ${ }^{2}$ \\ ${ }^{1}$ Prodi Teknologi Mesin, Politeknik Enjinering Indorama \\ ${ }^{2}$ Prodi Mekatronika, Politeknik Enjinering Indorama \\ Desa Kembang Kuning Jatiluhur Purwakarta, Jawa Barat \\ "Corresponding author: saf_89@yahoo.com
}

\begin{abstract}
Roll conveyor is one of goods transportation, especially for moving goods produced from the production location to storage places, mainly carried out in industrial areas and away from moisture. There is a conveyor roll transport that moves use gravity style, namely by making the angle of inclination between the moving source area to the targeted area, yet if the source area with the destination area, namely the storage of goods produced is horizontally flat, then a source is needed a driving source, one of them is using an AC / DC electric motor. Based on the results of testing the conveyor roll by giving a different loading is the no-load condition of a 60 Watt electric motor can be rotated $73.2 \mathrm{rpm}$ until the motor is finally able to deliver products with a load of 738,693 $\mathrm{N}$ with $71.4 \mathrm{rpm}$ rotation. This test shows that the decrease in roll rotation occurs in the range of $0.22 \%$, for an increase in the load of $49.05 \mathrm{~N}$ $(5 \mathrm{~kg})$. The graph results of the connection between loading and roller rotation show that the conveyor roll has a possibility to carry loads with a mass of about $150 \mathrm{~kg}$.
\end{abstract}

Keywords: conveyor roll, transportation, electric motor, rotation, load.

\begin{abstract}
Abstrak
Roll conveyor adalah salah satu alat transportasi barang, terutama untuk memindahkan barang hasil produksi dari lokasi hasil produksi ke tempat-tempat penyimpanan, terutama dilakukan dalam area industri dan jauh dari kelembaban. Transportasi roll conveyor ada yang bergerak dengan gaya gravitasi, yaitu dengan membuat sudut kemiringan antara daerah sumber gerakkan ke daerah yang dituju, tetapi jika daerah sumber dengan daerah yang dituju yaitu tempat penyimpanan barang hasil produksi merupakan daerah yang rata secara horizontal, maka diperlukan suatu sumber penggerak yang salah satunya adalah menggunakan motor listrik AC/DC. Berdasarkan hasil pengujian roll conveyor dengan memberi pembebanan yang berbeda adalah kondisi tanpa beban motor listrik berdaya 60 Watt mampu berputar dengan putaran 73,2 rpm sampai akhirnya motor tersebut mampu mengantarkan hasil produksi dengan beban 738,693 $\mathrm{N}$ dengan kecepatan 71,4 rpm. Hal ini menunjukkan bahwa penurunan putaran roll terjadi pada kisaran 0,22 \%, untuk peningkatan beban sebesar 49,05 N (5 kg). Hasil dari grafik hubungan antara pembebanan dengan putaran rol menunjukkan bahwa roll conveyor dimungkinkan mampu mengangkut beban dengan massa sekitar $150 \mathrm{~kg}$.
\end{abstract}

Kata kunci: roll conveyor, transportasi, motor listrik, putaran, beban

\section{Pendahuluan}

Conveyor dikenal sebagai peralatan tranportasi masal yang digunakan untuk memindahkan barang produksi dari satu tempat ke tempat lain dengan menggunakan seperangkat peralatan mesin. Peralatan tersebut ada yang dikenal dengan belt conveyor, scrue conveyor, dan roller conveyor. Semua peralatan ini sangat diperlukan dan dibutuhkan oleh banyak industri untuk memindahkan barang atau hasil produksi pabrik dari satu tempat ke tempat yang lain, apakah dalam jarak yang cukup dekat atau pada jarak yang cukup jauh [1][2]. Pilihan menggunakan konveyor untuk memindahkan barang merupakan suatu alternatif yang sangat bagus, karena dapat meningkatan efisiensi kerja terutama 
untuk area-area yang cukup sulit dan sempit jika dilakukan langsung oleh peralatan transportasi lain, seperti mobil, gerobak atau orang sekalipun [3][4][5]. Oleh itu perlu dilakukan suatu kajian tentang roll conveyor sebagai transportasi alternatif pengangkut/pemindah barang dari satu tempat ke tempat yang lain dan mungkin sulit dilakukan dengan jenis transportasi yang lain. Kajian akan lebih dititik beratkan pada permasalahan berapa cepat roll conveyor dapat bergerak untuk mengangkut suatu barang dengan berat tertentu dan pengaruh pembebanan terhadap perubahan kecepatan gerak roll conveyor.

Kajian ini diharapkan dapat membantu para pengguna dalam memilih suatu alat transportasi alternatif yang sangat efektif dan efisien, seperti untuk keperluan jasa transportasi seperti di daerah industri, pertambangan, department store, bandara penerbangan dan banyak unit-unit lainnya. Selain itu dari kajian ini juga diharapkan para pengguna dapat memilih dan menentukan berapa berat beban yang dapat diangkut untuk batas waktu tertentu yang direncanakan sehingga benar-benar merupakan suatu pilihan yang tepat sebagai sarana transportasi barang yang sangat tepat dan efektif.

Penggunaan roll conveyor di daerah-daerah indusri untuk mengangkut atau memindahkan barang hasil produksi, bukanlah sesuatu hal yang baru, karena diyakini dengan menggunakan roll conveyor dapat mengurangi biaya produksi dan juga dapat mengangkut hasil produksi dalam jumlah yang lebih banyak dan berat, karena konstruksi roll conveyor rata-rata dibuat rata dan tidak miring sehingga resiko terjadinya tumpah barang sangat kecil. Disamping itu juga diyakini dengan menggunakan roll conveyor hasil transportasi produksi dapat ditentukan setiap jamnya.

Bentuk konstruksi roll conveyor adalah sangat sederhana dan mudah untuk dipasangkan [1][2]. Pertama, roll conveyor terdiri dari susunan rol-rol, yang tersusun rapi pada jarak yang seragam. Diantara masing masing rol akan dihubungkan dengan rantai dan gear untuk menggerakkan roll conveyor. Penanganan roll conveyor adalah sangat mudah jika terjadi penggantian karena kerusakkan pada salah satu roll conveyor, maka hanya rol yang rusak saja yang akan diangkat dan diganti dengan rol yang baru, tanpa menggangu rol yang lain [6][7][8][9].

Sistem penggerak roll conveyor menggunakan motor AC yang terhubung langsung dengan as roll conveyor. Pengujian tahap awal dilakukan pergerakkan pada bidang rata, akan tetapi tidak menutup kemungkinan akan dilakukan pada tanjakan dengan kemiringan tertentu. Pada pengujian akan dilihat seberapa besar pengaruh beban terhadap perubahan gerakan roll conveyor sebagai sarana transportasi alternatif.

\section{Tinjauan Pustaka}

Roller conveyor adalah conveyor yang paling umum digunakan karena lintasan geraknya tersusun dari beberapa tabung (rol) yang tegak lurus terhadap arah lintasannya dan dapat menahan beban vang bergerak sesuai dengan arah putaran rol [1][2]. Roller conveyor biasa digerakkan dengan rantai atau belt seperti pada Gambar 1, ataupun dengan menggunakan gaya gravitasi tetapi harus diperhitungkan kemiringan maksimumnya.

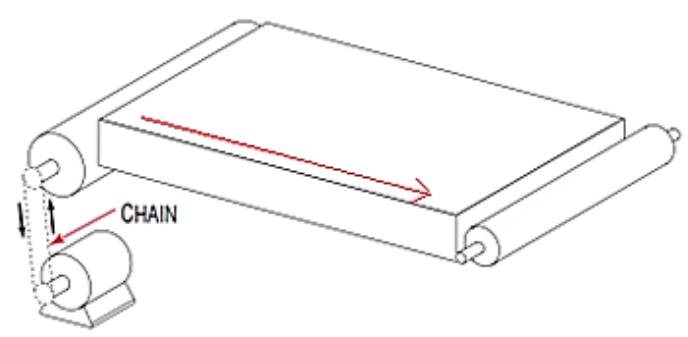

Gambar 1. Sistem kerja roll coveyor

Roller pada sistem roller conveyor didesain khusus agar cocok dengan kondisi barang yang dipindahkan, misalnya roller diberi lapisan karet, lapisan anti karat, dan lain sebagainya. Sedangkan roller pada sistem jenis yang lain didesain cocok untuk sabuk yang ditumpunya [1]. 
Besarnya daya yang diperlukan oleh sebuah sistem roll conveyor [2] dapat dihitung dengan persamaan berikut:

$\mathrm{W}=\mathrm{W} 1+\mathrm{W} 2+\mathrm{W} 3$

Keterangan:

$\mathrm{W} 1$ = bobot material

$\mathrm{W} 2$ = beban gesekkan

$\mathrm{W} 3=$ Faktor koreksi $(0,8 / 0,9)$

$$
W_{1}=\frac{G \times 2 K}{d}
$$

Keterangan:

$\mathrm{G}=$ berat benda kerja $(\mathrm{kg})$

$\mathrm{K}=$ koefisien gesek

$\mathrm{d}=$ diameter roller $(\mathrm{m})$

Komponen utama roller conveyor:

1. Kerangka badan: berfungsi untuk menopang roller agar lokasi roller tidak berpindah-pindah.

2. Tiang penyangga: berfungsi untuk pondasi kerangka badan sistem roller conveyor.

3. Motor penggerak: berfungsi untuk menggerakkan drive roller agar selalu berputar sesuai dengan kecepatan yang diinginkan operator.

4. Roller: berfungsi sebagai pemindah barang yang akan ditransportasikan.

5. Sistem transmisi: berfungsi untuk mentransmisikan daya pada penggerak ke sistem konveyor

\section{Metode Penelitian}

Untuk mendapatkan suatu hasil kajian secara aktual mengenai suatu alat transportasi seperti roll conveyor yang akan dianalisa terjadinya perubahan kecepatan rol dengan perubahan pembebanan [3][4][5], maka pengujian ini akan dimulai dari suatu perencanaan desain konstruksi, pembuatan, pengujian dan pembuatan suatu laporan hasil uji yang sudah dilengkapi dengan suatu analisis dan kajian secara aktual mengenai roll conveyor yang bergerak secara horizontal.

Spesifikasi motor sebagai sumber Penggerak roll conveyor:
Daya motor
: $60 \mathrm{Watt}$
Putaran motor
$: 1300 / 1600$

\section{Rasio putaran $\quad: 1: 20$}

Sebuah sistem roll conveyor yang nantinya akan diteliti, roll conveyor sebagai peralatan tranportasi hasil produksi di daerah industri, diawali dengan pembuatan sistem roll conveyor yang bergerak secara horizontal dan terbuat dari pipa galvanis sebagai bahan utama pembuatan rol dengan diameter $40 \mathrm{~mm}$, panjang $237 \mathrm{~mm}$, dan dengan lintasan $1500 \mathrm{~mm}$. Setiap rol akan dipasang pada konstruksi yang rata, berjejer dengan jarak yang sama $60 \mathrm{~mm}$, kemudian setiap roll akan dilengkapi dengan dua pasang roda gigi yang nantinya akan saling terhubung dengan rantai penggerak dan bergerak secara bersama-sama dalam memindahkan barang dari satu tempat ke tempat lain. Rangkaian konstruksi roll conveyor tersebut seperti yang terlihat pada Gambar 2. Roll conveyor akan digerakkan dengan menggunakan sebuah motor AC, dan pengujian roll conveyor akan dilakukan dengan pemberian beban dengan variasi pembebanan yang semakin meningkat. Dengan cara seperti ini akan diketahui pengaruh pembebanan terhadap kecepatan transportasi roll conveyor terhadap meningkatnya pembebanan [3][4][5].

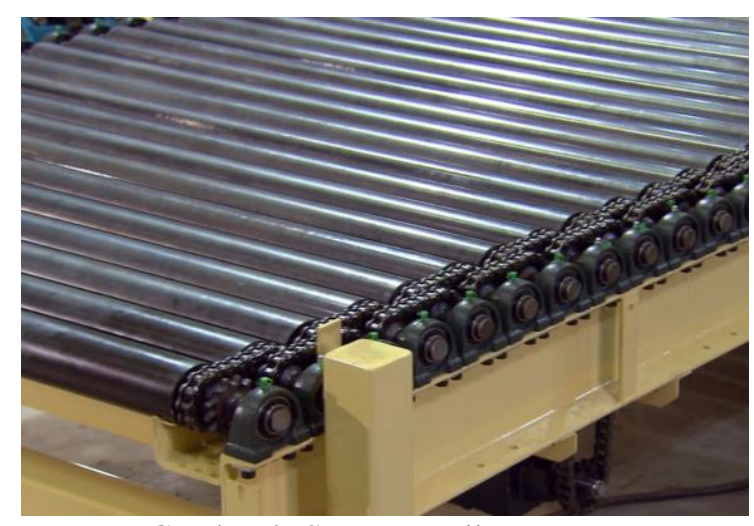

Gambar 2. Susunan roll conveyor yang direncanakan

Laporan hasil pengujian akan dibuat dengan format jurnal ilmiah nasional, yang akan dilengkapi dengan analisis hasil pengujian dan satu kesimpulan secara aktual, dan berdasarkan referensi- referensi standar teks books yang digunakan, seperti tertera pada data referensi. Hasil pengujian dapat dijadikan panduan dalam 
menentukan beban pada roll conveyor [3][4][5].

Desain gambar dan konstruksi sistem roll komveyor ditampilkan pada Gambar 3.

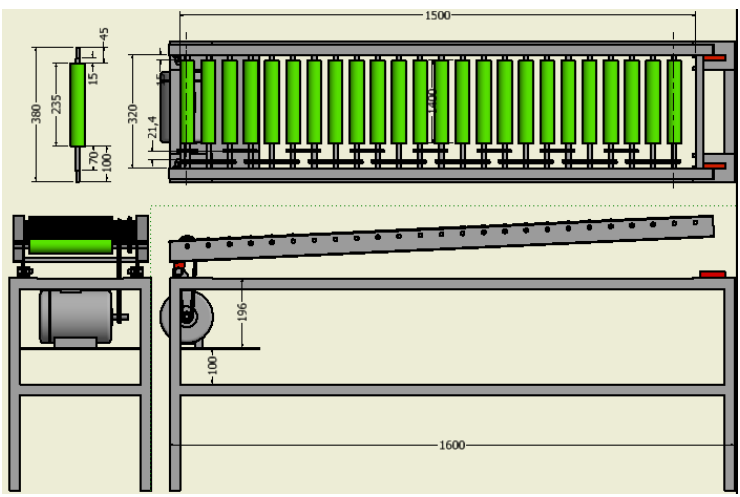

(a)

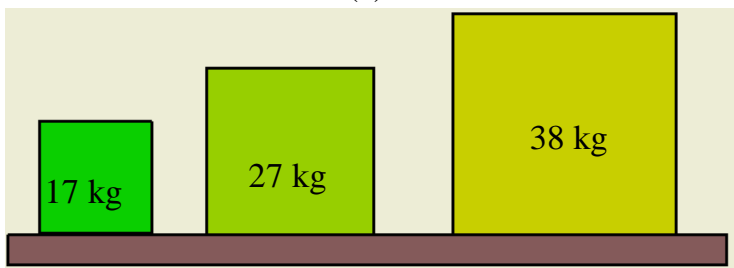

(b)

Gambar 3. Sistem roll conveyor dan beban [inventor], (a) Sistem roll conveyor, (b) Beban uji dengan variasi berat

\section{Hasil dan Pembahasan}

Pengujian dilakukan dengan massa pengujian $35 \mathrm{~kg}$ s/d $75,3 \mathrm{~kg}$ atau setara dengan berat beban $343,4 \mathrm{~N}$ s/d 738,7 N, seperti yang diperlihatkan pada Gambar 4 .

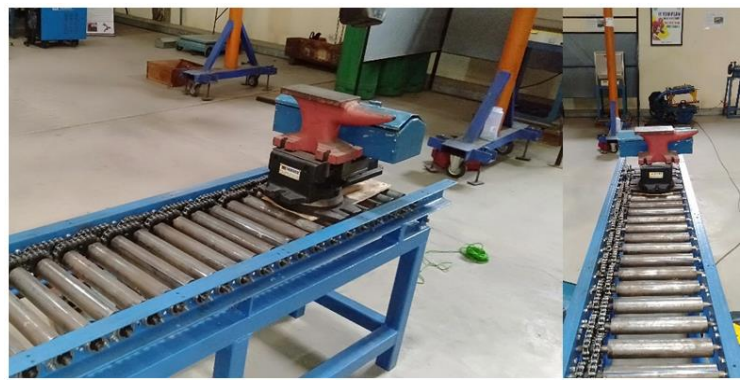

Gambar 4. Pengujian dengan massa $75,3 \mathrm{~kg}$

Pengujian diawali dengan putaran output motor tanpa beban sebesar 74,5 rpm, setelah terhubung dengan sistem roll conveyor kecepatan putar motor menurun hingga 73,2 rpm, dan selanjunya disebut kecepatan roll conveyor berdaya 60 Watt dengan kecatan awal 73,2 rpm (tanpa beban).
Untuk kecepatan putar roll conveyor akan diuji dengan pemberian beban yang secara berurutan seperti yang ditampilkan pada Tabel 1.

Tabel 1. Hasil pengujian

\begin{tabular}{cccc}
\hline No & Massa $(\mathrm{kg})$ & Beban $(\mathrm{N})$ & Putaran (rpm) \\
\hline 1 & 35 & 343,35 & 73,2 \\
2 & 43 & 421,83 & 72,7 \\
3 & 55 & 539,55 & 72 \\
4 & 65 & 637,65 & 71,6 \\
5 & 75,3 & 738,693 & 71,4 \\
\hline
\end{tabular}

Secara grafis hubungan perubahan beban dengan perubahan kecepatan putaran rol dapat juga dilihat pada Gambar 5.

Berdasarkan hasil spesifikasi motor satu fasa dengan daya 60 Watt dan putaran 1300/1600 rpm, dengan rasio kecepatan 1 : 20, artinya kecepatan output motor berkisar antara $65 \mathrm{~s} / \mathrm{d} 80 \mathrm{rpm}$. Setelah di uji didapat kecepatan motor sebesar 74,5 rpm (output motor tanpa beban sistem rol). Setelah dihubungkan dengan sistem roll conveyor, kecepatan motor turun sebesar $1,745 \%$ atau sekitar 1,3 rpm.

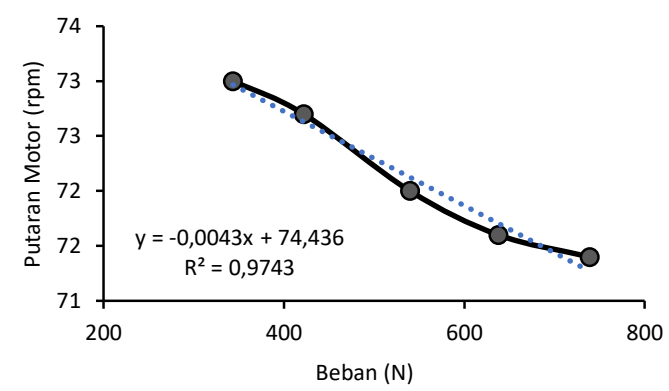

Gambar 5. Variasi beban terhadap putaran motor

Pada pembahasan yang telah ditampil pada Tabel 1 dan grafis pada Gambar 5, menyatakan bahwa kecepatan roll conveyor cenderung turun dengan bertambahnya beban. Penurunan putaran roll belumlah signifikan, dan hal ini dapat dilihat bahwa penurunan kecepatan hanya berkisar 0,06 \% s/d 0,5\%. Jika penurunan kecepatan tersebut dirata-ratakan maka penurunan kecepatan berkisar dengan nilai $0,22 \%$. 


\section{Kesimpulan}

Dari hasil pembahasan di atas dapat diambil kesimpulan bahwa kecepatan rol cendrung menurun dengan bertambahnya beban, meskipun dalam batas yang relatif masih kecil. Hal ini menunjukkan bahwa rol masih mampu membawa beban yang lebih besar dari massa $75,3 \mathrm{~kg}$ atau dengan beban 738,693 $\mathrm{N}$ bahkan sampai dengan massa 75,3 kg. Keadaan ini belum banyak memberikan dampak terhadap penurunan kecepatan putar rol, yaitu dengan kisaran $0,22 \%$. Hal ini menunjukkan bahwa roll conveyor dengan kekuatan daya 60 Watt masih mampu membawa beban dengan kisaran massa $150 \mathrm{~kg}$ atau beban $1471 \mathrm{~N}$.

\section{Referensi}

[1]. Chris McCauley Editor, Machinery's Handbook Industrial Press, Inc. 200 Madison Ave. New York.

[2]. Spivakovsky and V. Dyachkov. 2017. Conveyors and Related Equipment. Publisher Mooscow USSR.

[3]. Mr. Shital S. Bhosale, Prof. A. V. Gaur. 2017. Analysis of Powered Roller Conveyor using FEA. IJSRD International Journal for Scientific Research \& Development| Vol. 4, Issue 11: $107-111$.

[4]. S. M. Shinde, R.B. Patil. 2012. Optimization Technique Used for the Roller Conveyor System for Weight Reduction. International Journal of Engineering Research \& Technology (IJERT), Vol. 1 Issue 5: $1-10$.

[5]. Prayag. R. Shirolkar, Mr. Uday. B. Khadabadi Mr. Vikas Adavale. 2015. Contact Stress Analysis of a Roller Conveyor. International Research Journal of Engineering and Technology (IRJET), Volume: 02 Issue: 03: 1232 - 1235.

[6]. D.K. Nannaware, R.R. Kharde. 2014. Design and Optimization of Roller Conveyor System. International Journal of Scientific \& Engineering Research, Volume 5, Issue 7: $1254-$ 1258.
[7]. Hendri Sukma, ST. MT , Muhammad Sulaeman. 2019. Perancangan roller conveyor pemindah label berkapasitas $80 \mathrm{~kg}$. Seminar dan Konferensi Nasional IDEC: D09.1 D09.10.

[8]. Suhas M. Shinde and R.B. Patil. 2012. Design and Analysis of a Roller Conveyor System for Weight Optimization and Material Saving. International Journal on Emerging Technologies 3(1): 168-173.

[9]. Shital bhosale, A.V.Gaur. 2016. Analysis of Powered Roller Conveyor. International Research Journal of Engineering and Technology (IRJET) Volume 03 Issue 09: 1469 - 1474. 